\title{
The practice of innovation at brazilian public university: the case of the University of São Paulo
}

\author{
Luciane Meneguin Ortega ${ }^{*}$ and Vanderlei Salvador Bagnato
}

*Correspondence: luciane.ortega@usp.br USP Innovation Agency, University of São Paulo, Torres Oliveira, 76, Jaguaré, 05347-902 São Paulo, SP, Brazil

\begin{abstract}
Based on the understanding that innovation is knowledge being incorporated into products and methodologies which render society more viable on breaking into the business market, Universities, as, generators of knowledge, play a major role in this scenario. It is within this context that the University of Sao Paulo, Brazil, established the Technological Innovation Center-USP Agency of Innovation. Being within the academic community and belonging to a public institution, there are specific characteristics to be followed which may be unique for public institutions. In line with this philosophy, and based on a theoretical study, document analysis and reporting experience, this article discusses these issues and addresses, through a case study in Brazilian public university, the ways in which its Technological Innovation Center performs, through its process models and operational innovation. The analysis of this case study behind subsidies to discuss the practice of innovation implemented in Brazilian Public University and contributes to a theoretical and practical reflection on the role and the ways of how a university, facing its limitations and opportunities can perform innovation both internally and with its productive sector. The article comes even fill a gap on the scarce literature on how universities in developing countries, such as Brazil, practice innovation, demonstrating the importance of the results in this article to academia.
\end{abstract}

Keywords: Innovation, Innovation management, Public Universities, University of Sao Paulo, USP Agency for Innovation

\section{Background}

Innovation is in the agenda of any research institution nowadays. Obviously, everyone is aware that innovation is a word that is now in everyday use and is increasingly acknowledged as one of the main factors with a positive impact on competitiveness and economic development. Enterprises know that innovation is necessary in order to survive in a world as dynamics as ours, where products change not only in relation to their design, but also to their functional aspects. From a time perspective, many countries discovered this decades ago, but, in the case of Brazil, only a few years ago. This is why the country is attempting to speed up the process to enable innovation to really have the same impact on development as it did in North American and European countries. If we were to conduct an analysis from the perspective of the universities, what role should they play in the generation of innovation? Or furthermore, knowing their

(c) 2015 Ortega and Bagnato. This article is distributed under the terms of the Creative Commons Attribution 4.0 International License (http://creativecommons.org/licenses/by/4.0/), which permits unrestricted use, distribution, and reproduction in any medium, provided you give appropriate credit to the original author(s) and the source, provide a link to the Creative Commons license, and indicate if changes were made. 
specific characteristics, what are the ways of creating an environment which is suitable for the practice of innovation, without competing with other activities or replacing the same. Based on the principle that Universities should be generators of knowledge, which when appropriately processed becomes capable of generating direct benefits for society, they should assume a leading role in the process of practical innovation. This leading role should commence by taking into consideration that a university should not serve merely as a site for training human resources and course administrators, but needs to be a shaper of behavior and skills for the development of innovation with a direct impact on society. This scenario, with such questions and statements, leads the formulation of this article where we analyze a case study and presents reflections on the role of a public university and how to contribute to overcome the technological challenges.

It is within this context that this work presents what the University of São Paulo (USP) has been doing in relation to Brazil its Technological Innovation Center called USP Agency of Innovation, with regard to practical innovation, not only for the academic community, but also for external partners and society as a whole. This discussion and presentation of the modus operandi for innovation provides a model of how to practice innovation in a pragmatic manner at public universities.

However, in order to understand the role of public universities in developing countries regarding the practice of innovation it is necessary to consider key concepts regarding innovation and its management. There are numerous approaches to the issue of innovation. In theory, this work first addresses some of the concepts and the importance of innovation, and then goes on to deal with the management of innovation demonstrating the need for interaction between actors in the innovation system, where the University plays a role of importance. Regarding the role of the University, the article discusses its responsibility when it comes to innovation, presenting the context of the public university and its background face the technological challenges not only with its internal environment, but also with the productive sector. Following the literature review presents the scenario of Brazilian public university in terms of barrerias and opportunities in order to give subsidies to analyze the case study proposed by this article.

One of the great forerunners of the concept of innovation was the German economist Friedrich List (1789-1846). Concerned with finding means of helping his country achieve the same level of economic development as England after the Industrial Revolution, List advocated not only protection for the emerging German industries, but also proposed policies to speed up the industrialization process. Not by chance, List was a pioneer in the introduction of the concept of intangible investment, which he classified as the intellectual capital of the human race. As far as he was concerned, the current state of a country depends on a series of discoveries, enhancements and efforts of previous generations. If List was the forerunner of the idea of a "National Innovation System", the technology first began to be analyzed in depth with regard to the theory of economic development beginning with the works of Karl Marx (1818-1883), in the second half of the 19th century, and Joseph Alois Schumpeter (1883-1950), an Austrian economist and professor at the University of Harvard, in the first half of the 20th century. The work "The Theory of Economic Development" analyzed the role of entrepreneurs and inventors in the expansion of capitalism. In the opinion of the economist, these two categories of players had the gift of triggering waves of change in production processes, generating 
vast profit with the emergence of new products, processes and technologies implemented, while burning the bridges to the past and disposing of obsolete methods of production. According to Schumpeter (1950), any innovation produces what he defined as "creative destruction", whereby the new thrives alongside the old and then takes its place, leaving the dead and wounded behind, but boosting progress. According to this author, innovation is a means of obtaining a strategic advantage, and is responsible for the process of "creative destruction". This process involves a constant quest for the creation of something new which provides new sources of profitability, resulting in the destruction of old rules and the creation of new ones. Sawhney et al. (2006) underline the importance of the use, on defining innovation as the creation of a new and consistent value both for the consumer and the organization by means of the creative change of one or more of the dimensions of the system. The importance of innovation lies in the creation of value for the customer and the organization, or in other words, the creation of new products is not sufficient to innovate.

According to Tidd et al. (2008), innovation is something new which provides social value or wealth. Far more than a new product, something innovatory may be behind new technologies, new operational processes, new market practices, small-scale changes, adaptations, in short, new features which generate profit. In other words, the authors state that innovation implies a process which, generally speaking, involves knowledge, information and creativity. It should be pointed out that these in the opinion of these authors innovation should be regarded from three angles: technological innovation, market innovation and organizational innovation. As such, innovation "is driven by the ability to establish relations, identify opportunities and take advantage of the same” (p. 24).

Another contribution to the definitions of innovation comes from Bagnato (2012), based on the principle that innovation is knowledge being incorporated into products, processes and methodologies which render society more viable, on breaking into the business market. In other words, it is when a piece of knowledge generates a change which is absorbed by the population, by the market. Innovation then becomes more important as a natural means of implementing scientific knowledge. In days gone by, and particularly in the Middle Ages, humanity surrounded itself with spiritual protection.

European cities tended to expand around their cathedral, as this served as a refuge, a search for support for the protection and development of each individual from a spiritual point of view. Over time, people's life experience began to change and they started to realize there was more to life than spiritual factors, and began diversifying their points of attraction, paying greater attention to earthly nature and its vicissitudes. It has always been known that knowledge is vital. So much so that in times gone by wise men were kept close to kings and governors as advisors. Nowadays, the situation has been inverted: the knowledge of how nature works determines everything. People, despite continuing to need several kinds of support to live, including spiritual support, realize this not sufficient to determine their progress, either as an individual or economically speaking in relation to the inclusion of their countries in the modern world. Only the conversion of knowledge into innovation, into wealth, enables modern societies to achieve this progress and to secure prominent positions as a means of providing their citizens with the best possible welfare. 
This is reinforced by Tidd et al. (2008) (p. 35), who state that "..... innovation is a question of knowledge-of creating new possibilities through combining different sets of knowledge. These can be in the form of knowledge about what is technically possible or what particular configuration of this would meet an articulated or latent need".

Talking about configuration of knowledge being channeled into innovation stresses the importance of managing innovation. The work of Henderson and Clark apud Tidd et al. (2008) provides a key contribution to our understanding of this idea. They state that innovation rarely involves dealing with a single technology or market, but rather with a bundle of knowledge which is brought together into a configuration. Successful innovation management requires getting hold of and using knowledge about actors, but also about how these can be put together-which they termed the "architecture of an innovation".

According to Maculan (2002), innovation management requires of the organization a capacity to integrate and coordinate human, financial, technical and organizational resources for the generation of new ideas which will enhance products, services and processes; the creation of new knowledge; the development of solutions which will put these ideas into practice and the transfer of these results to the organization's practices. Innovation activities generally require interactions with a variety of actors comprising the innovation system. These components include government laboratories, universities, policy departments, regulators, competitors, suppliers and consumers.

In the case of the actors involved, we should emphasize the vital role of educational and research entities (particularly universities), which play a minimum dual role in innovation processes: that of generating scientific knowledge and of providing a skilled workforce capable of innovating. It is in this scenario that we need to address the role of universities in innovation management.

The 21st century features peculiar characteristics which have been under management since the second half of the 20th century. Although there is no consensus among the various authors on this period, some have termed it post-modernity. It is in this context that this work intends to (re) assess Brazilian universities with regard to space for the creation and disclosure of scientific knowledge, and, furthermore, space for training the citizens of the 21 st century and a new society.

What role should universities play in relation to the paradigm of post-modernity? How does one effective conduct activities involving the production and socialization of knowledge in a socially responsible manner? How do we convert the ideas generated in the university environment into wealth for use in the lives of people and organizations?

The ability of a nation to generate knowledge and convert it into wealth and social development depends on the performance of certain institutional agents dedicated to the generation and application of knowledge. The principal agents comprising a national system for the generation and appropriation of knowledge are companies, universities and the government. As such, what role do universities play? And what about public universities with their own specific characteristics?

The importance of the development of technology and innovation at universities is an almost universal concept. But how can this perception really be mirrored in the reality of these institutions? 
Universities need to understand that activities conducted in a university environment take on significant importance. Universities are no longer an institution for training human resources and course administrators, but are now shapers of behavior and skills for the development of innovation.

In the post-modernity era from a scientific viewpoint as a subset of the vast set of knowledge, learning is now related to practical skills such as know-how, savoir-vivre and the art of listening, thereby related to customs, and should, a priori, meet the practical demands of the working world, with a priority on applied research.

Or in other words, the general idea of a kind of "linear model" in the 20th century was consolidated, which suggests that innovation begins with basic research, followed by applied research, followed by development, and, finally, production and disclosure. The final two stages are regarded as those most associated with innovation. Moreover, what is clear today is that innovation is no longer a possible distant consequence of basic research or the end of the line. Innovation has often turned out to be the source of research programs, shaping and stimulating science to be produced as a consequence of the word innovation.

At the same time, the traditional assumption that innovation arises from the need to meet demand, has been replaced by the idea that, at times, innovation generates demand on a scale never previously imagined.

Hence, in accordance with the paradigm of post-modernity, this means rethinking the role of education in this trajectory, and within the different schooling institutions, universities should undoubtedly play a major role. How, based at a public university, can one create "prudent knowledge for a decent life"? The current stage of scientific and technological development does not match the development of human moral capacity, or in other words, the recognition of the responsibility of the self to the other. This lack of responsibility, this inability to think beyond the subjective desire of self-satisfaction, gives rise to the disasters which have marked society in recent times (Bauman 1998). As such, the primary role of society and its institutions shall be that of rethinking a new benchmark ethic for human relations and a brake on consumerism and the sovereignty of individual liberty in favor of a new collective order. In accordance with free discussion and debate, whose place, above all, is at public universities, we need to discover and create the foundations for the advent of a society based on justice.

The triple helix concept developed by Etzkowitz and Leydesdorff (1995) assumes that the university, in accordance with the post second revolution, should be an entrepreneurial university with the following characteristics: basic research with business potential; a tradition in business start-ups; an entrepreneurial culture on the Campus; policies defining rules for the appropriation of intellectual property; the sharing of profit and regulation of conflicts of interest; and participation in the regional innovation strategy (Etzkowitz and Zhou 2006).

Thus, the entrepreneurial university is the base for regional economic development, encompassing teaching, research and services to society, not as a linear process, but as spiral feedback involving the constant accrual and distribution of knowledge. According to Etzkowitz (2008), when the university assumes a new role in the promotion of innovation, its missions in relation to education and research also change. Paradoxically, the greater the influence of the university on society, the more it is subject to the influence of 
society, which in this sense is desirable, given public research universities are financed by society to generate common benefits for the same.

The importance of the development of technology and innovation at universities is an almost universal concept. But how can this perception really be mirrored in the reality of these institutions? And what is the importance of the relationship between the universities and the companies for which innovation effectively occurs? It is believed universities need to be given priority, as without the training of skilled professionals and the generation of scientific-technological knowledge, companies will lack the most important source of basic scientific knowledge, due to the fact it is the university environment which generates the ideas which can be turned into wealth for use by individuals and organizations.

However, the companies are not only responsible for the role of converting scientific knowledge into innovation, as they can and should generate ideas for new solutions for the problems facing the economic agents. As such, the company also needs to conduct research and development activities, which are often similar to the research conducted at universities. Only there is a small detail here: companies, in principle, do not train or generate professionals, but use the knowledge of individuals. This is why there is a need for the partnership between the universities, the trainers of human resources and providers of the innovators, and the companies, which take in these professionals to develop their technology and to create innovative material for the market. Hence, at the end of this line of thought, we conclude that there is a need to strengthen relations between the universities and the companies. The company needs to report its requirements to the universities. Failure to do so will make it almost impossible for the universities to provide what the companies need in terms of human resources and knowledge, and it is almost impossible for the companies to absorb the knowledge of the universities if the same is only contained in scientific articles. Hence, the company-university relationship is vital for a model capable of achieving success in this new trend of economic development based on technological innovation. The role of the university is to be the generating hub of scientific border knowledge, and, in partnership with the companies, transform this knowledge into technology products for the market, positively changing the living standards of the people and everything which is done for society in the quest for well-being.

The academic environment needs to be a generator of new ideas. Academics, above all others, are responsible for the generation of ideas, in addition to assembling laboratories and the production of human resources for the quest for knowledge, be it for immediate technological use or not.

But this alone is not enough. When science is being produced one can extract a small fraction to be transformed into a product to meet a need of society and to create economic wealth. Hence, to ensure innovation exists in the academic environment it is not necessary for the application of knowledge to be given priority over the generation of knowledge, as knowledge represents the great pillar which supports the use of the same.

Both the generation and the application of knowledge are important. The application of knowledge, in turn, should accompany the generation of knowledge, to ensure the knowledge is implemented in a competitive and accurate manner. Technological innovation arises, therefore, from the application of the knowledge generated at the institutions 
of education. Thus, innovation in the academic environment goes beyond the science of good quality and not "instead of" it. It is no coincidence that the major global centers of basic science are also the major centers of technological innovation. If we take the ten best universities in the world, we will see that they are not only the biggest producers of science, but also the ten which are most concerned and busy with technological innovation. So, how do we create a situation where technological innovation becomes part of the natural routine of the academic environment? First of all these activities should be well coordinated. Technological innovation must be a part of the day-to-day activities of the university. Researchers at these institutions need to be ready to use, whenever possible, their ideas and results for the good of society and not merely for the good of the evolution of knowledge. This is where the greatest innovations of all time are. Thus, an academic environment should feature sectors which generate technological activity on a daily basis.

In the case of developing countries, such as Brazil, the practice of innovation through public universities it is very incipient and it needs to be enhanced through the adoption of specific measures. There is also a limited literature to be able to clarify how the universities of such countries practice innovation, demonstrating the importance of the results in this article to academia.

Thus, seeking to contribute to scientific research, this work exposes the context Brazil and more specifically, the context of a Brazilian Public Univeridade and ways to practice and manage innovation.

With regard to Brazil, the city of Sao Paulo today has the University of São Paulo (USP) and innovation management is the responsibility of Technological Innovation Center called Agency for Innovation, the function of which is to create an environment at the university geared to the practice of innovation, without competing with other activities or replacing the same. To the contrary, strengthening the generation of scientific knowledge and the training of human resources, while taking advantage of everything possible for the generation of technological innovation.

Bolstered by this theoretical study, this paper aims to present and analyze as a brasileria public university can practice innovation and technological innovation challenges in order that the results may bring contributions to a theoretical and practical reflection on the role of public university in the form to manage their innovation in developing countries.

\section{Methods}

Regarding its nature (or goals), the article is classified as exploratory and descriptive. Exploratory studies seconds Gil (2006, p. 43) provides overview about certain fact, particularly if the chosen topic is largely unexplored. Complementing this concept, according Selltiz et al. (1974, p. 60) a search is considered as exploratory, deepens knowledge on the subject, favors a more structured follow-up study, clarifies concepts, establishes priorities for future research and formulates future problem for more accurate research or creating chances. Therefore, it is considered the theme of this exploratory work since reported knowledge on a subject little explored in academic studies of innovation is innovation management in developing countries and more specifically in Public University. Your goals favoring the exploratory nature since this favors further research on 
the topic. The classification as a descriptive study takes place as these are intended to describe certain population characteristics or phenomenon or establishment between variables (Gil 2006, p. 44). Therefore, considering the characteristics and complexity of this study, this study is an exploratory and descriptive study, looking outline limitations of the Brazilian public university with respect to innovation management and the forms used for such University to manage and practice innovation in its internal and external environment to their environment.

Regarding the research method, this article is classified as a case study. The case study can be characterized as an empirical investigation in which phenomena are analyzed within its real context and the researcher has no control over the variables and factsdeeply analyze a social unit and requires high interaction of the researcher with the environment and its actors in order to understand the dynamics between them (Martins and Theóphilo 2009; Eisenhardt 1989). There is also the definition of Yin (2010) which states that the case study is an empirical research "investigates a contemporary phenomenon in depth and in its real life context, especially when the boundaries between phenomenon and context are not clearly evident" (Yin 2010, p. 39). In this article we present a single case study, reporting to NIT experience of the Brazilian Public University-University of São Paulo.

As for the means of investigation, the search is bibliographical and documentary, but it will be from the authors' experience in the NIT management concerned. The literature review will include a review of the literature on the subject themes of this study, based on material published as books, articles published in professional journals or presented at scientific-technical meetings in order to theoretically base the analysis of the data and work on itself. Desk research is intended for the collection, analysis and interpretation of documents (plans, reports, the institution database investigated) since the creation of NIT at the University of São Paulo, that is, from the year 2005. With regard The third means of investigation using the argument of Biancolino et al. (2012), the technical report of approach prioritizes professional experience and the practice of researchers is therefore appropriate for this study. The authors of this article are to lead the Technology Innovation Center (NIT), University of São Paulo (USP) 3 years and 6 months, and since then, are facing difficulties and opportunities, giving subsidies to discuss this article about his experiences in the practice of innovation implemented in Brazilian public university.

The University of São Paulo located in southeastern Brazil, established in 1934, is a public university, maintained by the State of São Paulo and linked to the State Secretariat for Economic Development, Science and Technology. It has about 92,792 students, 6008 teachers and approximately 17,450 employees in its 87 units, 42 focused on teaching and research. It offers 289 undergraduate and 222 graduate programs. Placed in the context of this University the study's focus is to use up the experience lived by one of his organs called USP Agency of Innovation and activities that seek to provide innovation in the context of a Brazilian Public University.

Regarding the sample, the article presents limitations in that report the experience of a single core Brazilian technological innovation that is the University of São Paulo, giving banks the future studies expanding the scope involving other Brazilian public universities of relevance. However, the presentation of the results of this work are able to 
demonstrate their theoretical and practical contributions to alternatives ways to manage innovation in a context of public university in spite of its difficulties and opportunities.

Based on the theoretical and documentary study, coupled with the experience lived by the authors, the article presents below the results and discussions of selected case study (NIT University of São Paulo), demosntrando their way of managing innovation and featuring discussions barriers and opportunities experienced or to be taken into account.

\section{Results and discussion}

In this scenario of the quest for innovation, globally, each university has been involved in designing the best possible management model for promoting and boosting innovation.

In the case of Brazil, faced by the demand for the academic sector to participate in the economic development of the country, going beyond the evolution of knowledge and the training of human resources, the issue began to intensify on the implementation of the Law on Innovation (BRAZIL, 2004, Law 10.973/2004). Motivated by this fact, in 2004 the University of Sao Paulo (USP) created the Technological Innovation Center (NIT), known as the USP Agency for Innovation, in accordance with the terms of the aforementioned Federal Law and the Sao Paulo Law on Innovation (Supplementary Law NO 1049 of 19.06.2008). The Agency reports to the Pro-Rectory of Research and is headed by the Coordinator and Deputy Coordinator, both professors at the university, appointed directly by the Chancellor.

Due to the geographical layout of the USP campuses, the Agency is decentralized, operating from the campuses of Sao Carlos, Piracicaba, Lorena and Ribeiro Preto, in addition to the Main and East campuses in the city of São Paulo itself. This ensures greater and better proximity to the researchers. At the close of 2013 the USP Agency for Innovation boasted a workforce of 23 employees, 5 scholars and around 36 interns. The high number of interns illustrates the Agency significant leaning towards education. Employees are hired through a public tender process, which enables the planning of long-term activities and organization, which is not normally possible when dealing with temporary contracts. The workforce includes innovation agents, all of which hold at least a university degree in the different areas of knowledge, thereby contributing to the dynamic nature of the activities, in addition to employees providing support for the management of intellectual property, administration, technology transfer and entrepreneurship and educational activities. The Agency also has trainees, all of which study at USP in one area or another, contributes to enhancing the training of the undergraduates in a practical manner, setting them apart from the other internships.

The USP Agency for Innovation operates on different fronts and features activities geared to both the academic community and to establishing connections with external partners, addressed in this article via its operational model and innovation processes.

The protection of intellectual property generated by USP researchers is an important tool for innovation, involving guidance and support for the researchers to ensure the protection of the knowledge generated; the search for background knowledge on patent and trademark databases; the definition of legal and market strategies for the protection of creations; the drafting and filing of patents; the management of the patent portfolio with government entities; the organization of training and disclosure courses on the issues in question; the analysis and monitoring of patent reports drawn up by industrial 
property agents; the registration of brands, software, cultivars and copyright. The area of patents enjoys the support of an outsourced office hired via a public tender process, entrusted with the background search and wording of national patents, whereby registration, monitoring and management with the National Institute of Intellectual Property is conducted by an internal team. USP is one of the leading patent filers in Brazil, with 1100 patents registered filed with the National Institute of Intellectual Property. Such actions are all to meet internal demand to the university. However, the USP Innovation Agency also offers programs for potential partners who want to pursue university as strong knowledge. As an example there is a program called Vocation Innovation aimed at contributing with initial guidance to the USP's foreign community on issues related to innovation.

Another way to manage innovation virtually the NIT is the area of Technology Transfer, facing the proactive activity for licensing. As such, the work involves assessing the market potential of the inventions, conducting analyses of the technologies received in order to classify the same. In the event the patent is successfully licensed, $50 \%$ of the royalties received are handed over to the researchers, $40.5 \%$ to the research department and $5 \%$ to the rectory. Since the Agency was founded 32 licenses have been granted, and almost R\$ 1 million was received in royalties in 2013. Private initiative sees the Agency receiving demand in relation to technological areas of interest and conducts activities (workshops, events, meetings, directed search, etc.) identifying laboratories and researchers with the aim of generating new joint research and development projects. A vital cog in innovation management at USP, the researchers participate in all the stages: suggesting the ownership percentage at the start of the partnership, assisting in the wording of the descriptive patent report and conducting the technology and knowhow transfer process. The management of intellectual property in partnerships involving USP/Companies/Promotion Agencies/Foundations entered into via research covenants and/or contracts is defined in a specific clause, as a means of ensuring prior parameters in relation to co-ownership of applications for the protection of the different types intellectual property, including the prior commitment with regard to industrial and business exploitation of the results of the partnerships. The Agency helped process 491 covenants in 2013, involving agreements entered into between public entities or between public and private entities for the implementation of activities of mutual interest to the participants, such as the development or enhancement of new products or processes. Legal support is geared to the institutionalization and execution of the University's research and innovation policies and provides advice on the analysis of issues involving structuring and how to bypass legal barriers hampering the development of research and innovation at the University. A legal and technical advisory department was recently created to train work groups geared to parks and incubators associated with USP.

In the area of entrepreneurship and education the Agency strives to provide support for entrepreneurship within the university and in the relationship between the same and society. The activities range from the disclosure of entrepreneurial culture, the promotion of the generation of technologies within the spin-off concept, to support for the training and governance of innovation habitats (technology parks, incubators and local production clusters) linked to USP and the governance of the same in charge of promoting and supporting USP-Companies cooperation. It works with so-called junior 
companies that are still students initiatives within the university. Recently it is also taking actions with graduates of the University and entrepreneurs using their respective business experiences as mentoring along with co-working environments, technology parks and incubators.

The Agency is also active in the disclosure of technology by means of the Technology Disclosure Program, the primary purpose of which is to democratize the knowledge generated in the university environment. Via a partnership with the Brazilian Technical Response Service-SRBT, the Agency provides free technological information in the form of technical reports. This service enables entrepreneurs to consult technical responses and technology dossiers to improve the quality of products or services in the different sectors of agri-business, industry and services. In relation to the stimulation of undergraduates, the USP Pro-Rectory for Research and the Agency run the Entrepreneurship Scholarship program, which offers 150 scholarships a year to students currently enrolled at any branch of USP. The Agency also offers courses for the internal and external USP community in the form of activities with professors and students, as is the case of the optional free half-classroom course on "Innovation and Entrepreneurship", aimed at USP students; and the refresher course in partnership with the State of Sao Paulo (via the Federation of Industries of Sao Paulo-FIESP)"Management and Execution of Technology Innovation Projects" aimed at professionals trained to operate as corporate innovation managers. In terms of partnerships geared to Innovation and Entrepreneurship, the USP Agency for Innovation constantly promotes a variety of events and partnerships to promote the disclosure of the culture of entrepreneurship and innovation.

Faced with this scenario researched it is clear that the guiding principle of the USP Innovation Agency lies is the fact that the academic environment needs to generate new ideas for the benefit of society. Academics, above all, are required to generate ideas, in addition to assembling laboratories and producing human resources for the search for knowledge, be it for immediate technological use or not. But this alone is not enough. When science is being produced one can extract a small fraction to be transformed into a product to meet a need of Brazilian society and to create economic wealth. Both the generation and the application of knowledge are important, as innovation then arises from the application of the knowledge generated at the institutions of education. Hence, it is believed that the university environment is where ideas are generated rather than products. And these ideas are the seeds which, duly fertilized and cared for, result in innovations.

So where do the companies come in? In a simplified manner, it can be said that the first three phases of technological innovation, from the idea to the prototype, can be successfully developed in the academic environment. However, the activities involving initial testing, transforming it into a product, finding the market and concluding the innovation process need to be dealt with by the company. Hence, universities and companies need to be partners in order to ensure the seed of innovation grows in a healthy manner and is harvested. In many countries innovation and the connection with the company is guaranteed. In Brazil the phase involving the preparation of the customer for innovation is still under development. Most companies here don't believe in the concept of using ideas generated at universities to improve their performance. The University, therefore, must strive to introduce the culture of innovation to the production sector 
by means of different activities. And how can the clientele be generated to finalize the innovation process? In this scenario, the USP Agency for Innovation strives to generate clientele in several different ways. One is to generate the entrepreneurial student, the student that leaves university determined not to find a job, but to generate jobs. Another way is to seek out and form partnerships for the creation of spin-off companies arising from the research laboratories themselves, where ideas are developed up to the concept phase and often up to bench prototype phase, but which do not extend to the manufacturing phase. Hence, the USP Agency for Innovation is geared to the implementation of the program to facilitate the emergence and maintenance of these spin-off companies, somehow creating the clientele to use the technological innovation being created. Or even by installing companies' laboratories on the university premises as a means of bringing the corporate environment closer to the research conducted by the universities.

However, it notes that in developing countries this journey is just beginning. With seen through the theory, in many countries is guaranteed on innovation and relationship with society. Universities in North America hold comprehensive and wide-ranging agreements with companies, large, medium and small. In Europe, the academic environment is also impregnated with companies with an eye on the intellectual development of the universities. In countries such as Spain there are cases of research institutes where half the premises are occupied by companies and half by the university, in a process aimed at sharing physical space and the creation of synergies in relation to innovation activities. In such situations the knowledge of the universities finds its way to the production sector naturally and generates important innovation. This is not the case in Brazil.

Brazil is in a stage of development where the clientele for innovation is still under development. Most companies do not believe in the concept of using ideas generated at universities to improve their production and performance, or even can not wait for the time required by the legal part of the university in relation to the partnership agreement or red tape. As such, the universities are preparing themselves to generate knowledge which results in the creation of wealth, by means of technological innovation, whilst the companies do not seem to be prepared to absorb such knowledge. Thus, there is still a lack of clientele in Brazil to consume the technological innovation generated in the academic environment. The universities are attempting to introduce the culture of innovation to the production sector by means of several different activities. This is due to the fact they are aware of the importance of the production sector in the process for the creation of innovation which is valuable to society. And they are preparing themselves for this, receiving government incentives to produce technological innovation in partnership with companies and to be in a permanent state of alert to ensure the ideas are put to good use. The universities are thereby obliged to generate the clientele.

\section{Conclusions}

The analysis conducted by Youtiea and Shapira in 2008, and reiterated herein, states that traditional universities in general live in the past and see themselves as warehouses or accumulators of old knowledge. On the other hand, modern universities see themselves as generators of new forms involved with the advance of technological innovation and economic development in their region. With regard to innovation as a central issue, the universities are simultaneous generators of key ideas, particularly motivated by 
external demand, and stores of knowledge in our society. The manner in which knowledge is developed, disclosed and applied affects not only the cultural wealth of society, but global competitiveness too. The search for sustainable social and economic development and the challenges associated with competitiveness and for a better understanding of the joint work required between the universities and the production sector is going to demand new strategies for education in general, and a deep-rooted discussion on the methodologies compatible with the training of professional workers in a scenario in which innovation and sustainability are essential.

The mission of the universities within this ideological framework is limited to training higher quality technicians and cutting-edge techniques: the aim is to guarantee the advance of production, of productivity and of economic efficiency. The disclosure of this technical knowledge would resolve the problems of society. Economic and technological development is seen as the solution to our domestic problems. Science and technique work as elements of ideology and dominant interests, as elements for hiding the intricacies of social domination. While upholding this model, public universities tend to produce naive scientists and professionals capable of criticizing the technique but incapable of understanding the economic and social interests involved. This model is undergoing a crisis. The issues of contemporaneity and the speeding up of the dynamics of knowledge and the markets are increasingly in need of a professional with the ability to think creatively and flexibly, who is adaptable to new, unexpected situations, and, above all, who is sensitive to the issues of society and democracy.

Innovatory culture is essential to the progress and development of modern society. To innovate is to constantly strive for knowledge and transform the same into benefits for society, in the form of brand new products and services. The University, as a natural environment for creation, has a lot to contribute and to serve as a disseminator of this culture. Innovation automatically leads to a quest to market these results, this being one of the most effective manners of revitalizing and modernizing the economy. The guarantee that this may occur in the correct fashion, with the due credit going to those who turned the ideas into reality, requires documentation and records. The obtainment of intellectual property (patents, trademarks, etc.) involves a detailed procedure which needs to be conducted correctly in order to ensure success, in addition to avoiding future problems. Despite specialist terms to deal with this issue, it is of paramount importance that all the different participants in the process are aware of the issue. This ensures things run smoothly and that the process involving the use of intellectual property by third parties is conducted in the correct manner.

The universities are also responsible for the growth of their surroundings. In the case of Brazil, and returning to the issue of the current growth of our cities, it is clear the cities with universities and research institutes have turned into attractive economic hubs and undergo greater development. The cities with no centers of knowledge are attempting to implement the same via the creation of universities and by creating and attracting businesses. This is due to the fact that innovation, which is the transformation of knowledge into goods and services which are of use to individuals and organizations, is high on the development agenda of any modern society. Hence, if on the one hand it is important governors and leaders are aware of this and strive to implement these hubs of interest, on the other, scientists, professors, researchers and entrepreneurs need to 
be aware of the importance of the task of converting knowledge into goods and services for society. If on the one hand, the profit from the innovation does not go to the institution itself, but to the society it serves, on the other it should have certain entrepreneurial characteristics with no exaggeration or the definition of being just another business office, or even an intellectual property service. Undoubtedly, an Agency for Innovation within the University of Sao Paulo cannot wish to be a patent office, and as such all the academic involvement and an understanding of the system for the use of the knowledge by the different sectors of society is required. As such, the University of Sao Paulo is convinced of its role within the country's innovation processes. It also understands that innovation in Brazil goes beyond "business". We need to create the culture, the customers and the habit of looking out for and taking advantage of the opportunities arising from research. The best infrastructure in the country for conducting innovation is that of the academic environment and needs to be made use of by the production sector. Obviously, mechanisms to ensure this occurs smoothly need to be established. Companies need to be better prepared with a research laboratory or department to serve as a bridge between the company and the university at which joint efforts are now required. Enhanced innovation at Brazilian companies needs to undergo radical progress. This, however, will not occur without the mass participation of the universities. USP is most certainly prepared for such activity. As such, the role of USP in the country's technological overhaul consists of the awareness and understanding of the real role of the university in the process involving the creation of a national technological power. It is not only the organization of ideas and prototypes which is important, but also the generation of a conscience in the training of human resources. After all, should we train people to "look for" a job or to "generate" more jobs?

From an entrepreneurial point of view, Brazilian enterprises need to create a framework which not only ensures the practice of innovation, but which also transforms the stages of innovation into a reality close to that which occurs at the universities, where ideas proliferate on a constant basis. A company's research laboratory or department should be the bridge between the company and the university. How can we improve innovation at Brazilian companies? Less talk and more action, a culture of innovation within companies and the training of new people with this objective.

However, in order to ensure this innovation process really occurs and to the extent the country needs, a joint effort is now required, where both the academic and private sectors acknowledge the need for unity, different to coexistence, enabling the entire innovation process to be optimized and to achieve the desired success in the shortest possible timeframe, and, finally, generating suitable conditions of socio-economic development for the Brazilian people.

Reflect on the innovation process of a Brazilian public university opens thus scope for future research as a way to theoretically contribute to the literature, but also to clarify peculiar characteristics of developing countries that are alternative ways to practice innovation, despite their opportunities and difficulties.

Authors' contributions

Both work together in coordinating the study hospital and seek to practice together all the activities described in this work. Both authors read and approved the manuscript. 


\section{Authors' information}

The authors are coordinators of the USP Innovation Agency, case study described at work. They have different and complementary profiles: one is executor of innovation with experience in basic science and implementation of the same in society and the other acts in the management of the innovation process. In addition to this core coordinators of Technological Innovation, both are professors of the University of São Paulo.

\section{Acknowledgements}

We thank the USP Innovation Agency that contributed to the design and data acquisition involving coordination for the writing of the manuscript.

\section{Compliance with ethical guidelines}

Competing interests

The authors declare that they have no competing interests.

Received: 13 March 2015 Accepted: 27 August 2015

Published online: 14 September 2015

\section{References}

Bagnato VS, Perussi Filho S, Barriounuevo WR (2012) Inovação. Da teoria à prática. Caminhos da Inovação. São Carlos,

Compacta Gráfica e editora, capítulo 1, p 498

Bauman Z (1998) O mal-estar da pós-modernidade. Zahar, Rio de Janeiro

Biancolino CA, Kniess CT, Maccari EA, Rabechini R, Jr (2012) Protocolo para Elaboração de Relatos de Produção Técnica.

Revista de Gestão e Projetos - GeP 3(2):294-307

Brasil (2004). Law on Innovation. Law 10.973/2004

Eisenhardt KM (1989) Building theories form case study research. Acad Manag Rev 14(4):532-550

Etzkowitz H (2008) The Triple Helix: university-industry-government innovation in action. Routledge, New York

Etzkowitz H, Leydesdorff L (1995) The Triple Helix of university-industry-government relations: a laboratory for knowledge based economic development. EASST Rev 14(1):11-19

Etzkowitz H, Zhou C (2006) Regional innovation initiator: the entrepreneurial university in various Triple Helix models. Conference Theme Paper, 6. 2006, Singapore. Anais Singapore

Gil AC (2006) Como elaborar projetos de pesquisa. Atlas, São Paulo

Maculan AM (2002) Tecnologia, Conhecimento e Gestão das Inovações. Nota didática ITOI-PEP-COPPE-UFRJ, p 1

Martins GA, Theóphilo CR (2009) Metodologia da investigação científica para ciências sociais aplicadas, 2 edn. Atlas, São Paulo

Sawhney M, Wolcott RC, Arroniz I (2006) The 12 different ways for companies to innovate. MIT Sloan Manag Rev 47(3):7 Schumpeter J (1950) Capitalism, socialism and democracy, 3rd edn. Harper and Row, New York

Selltiz C et al (1974) Métodos de Pesquisa nas Relações Sociais. Tradução de Dante Moreira Leite, 3 edn. Editora da Universidade de São Paulo, São Paulo

Tidd J, Bessant J, Pavitt K (2008) Gestão da Inovação, 3a edn. Porto Alegre, Bookman

Yin RK (2010) Estudo de caso: planejamento e métodos. Bookmann, Porto Alegre

\section{Submit your manuscript to a SpringerOpen ${ }^{\circ}$ journal and benefit from:}

- Convenient online submission

- Rigorous peer review

- Immediate publication on acceptance

- Open access: articles freely available online

- High visibility within the field

- Retaining the copyright to your article

Submit your next manuscript at $\mathbf{s p r i n g e r o p e n . c o m ~}$ 